\title{
Litter Quality and Microbes Explain Aggregation Differences in a Tropical Sandy Soil
}

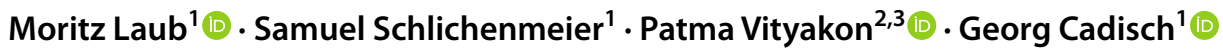

Received: 4 May 2021 / Accepted: 10 November 2021 / Published online: 29 November 2021

(c) The Author(s) 2022, corrected publication 2021

\begin{abstract}
Soil aggregates store most soil organic carbon (SOC), but how does litter quality influence their formation? We hypothesized varying litter quality to facilitate differences in aggregate formation by altering the seasonal development of microbial biomass (MB) $\mathrm{C}$ and N, with MB driving aggregate development in a tropical sandy soil in Thailand. Aggregate development was studied in a long-term fallow experiment, receiving $10 \mathrm{Mg} \mathrm{ha}^{-1}$ annual applications of rice (Oryza sativa) straw (low $\mathrm{N}$ and polyphenols (PP)), groundnut (Arachis hypogaea) stover (high N, low PP), tamarind (Tamarindus indica) litter (medium $\mathrm{N}$ and PP), or dipterocarp (Dipterocarpus tuberculatus) leaf litter (low N, high PP) compared to a control. N-rich litter from groundnut and tamarind led to significantly higher $\mathrm{MB}$, bulk soil $\mathrm{C}$ and aggregate $\mathrm{C}$ than dipterocarp, rice straw, and the control. Bulk soil $\mathrm{C}$ and small macroaggregates $\mathrm{C}$ of $\mathrm{N}$-rich litter treatments increased about $7 \%$ in 30 weeks. Increasing MB $\mathrm{N}$ explained increasing small macroaggregate $\mathrm{C}$ and both, $\mathrm{MB} \mathrm{C}$ or $\mathrm{N}$ were important covariates explaining temporal variations of $\mathrm{C}$ stored in the microaggregates, in silt and clay. $\mathrm{MB}$ also explained temporal variations of aggregate fraction weights. With time, SMA C only increased in the N-rich groundnut and tamarind treatments, but decreased in other treatments. Connections of $\mathrm{MB}$ to aggregate $\mathrm{C}$ and weight substantiated the importance of microbial activity for aggregate formation and carbon sequestration. By promoting MB for longest time spans, medium-quality tamarind could best facilitate aggregate formation, and increase silt and clay $\mathrm{C}$.
\end{abstract}

Keywords Soil aggregates carbon $\cdot$ Soil organic carbon $\cdot$ Soil fertility $\cdot$ Microbial carbon use efficiency $\cdot$ Microbial biomass

\section{Introduction}

The amount of soil organic carbon (SOC) is a crucial indicator of soil fertility, especially in tropical sandy soils with low clay contents. While the connection between SOC content and the amount of water stable soil aggregates (Tisdall and Oades 1982) is not a new idea, early studies mainly investigated the effect of abiotic factors on aggregates. They showed, for example, that tillage can lead to a breakup of

Moritz Laub

moritz.laub@usys.ethz.ch

1 Institute of Agricultural Sciences in the Tropics (HansRuthenberg-Institute), University of Hohenheim, 70599 Stuttgart, Germany

2 Department of Soil Science and Environment, Faculty of Agriculture, Khon Kaen University, Khon Kaen 40002, Thailand

3 Soil Organic Matter Management Research Group, Khon Kaen University, Khon Kaen 40002, Thailand macroaggregates, thus reducing SOC sequestration (Six et al. 2000). More recently, the role of microbes in aggregate formation has gained attention, recognizing that aggregates are stabilized by microbially produced binding agents, such as extracellular polysaccharides or fungal hyphae (Chenu and Cosentino 2011; Totsche et al. 2017). For their growth, microorganisms depend on organic resources to feed on. Thus, litter quality, defined by the ratio of lignin and polyphenols to litter $\mathrm{N}$, with a higher ratio corresponding to lower quality (Palm et al. 2001; Kunlanit et al. 2014), has a direct influence on microbial growth. Microorganisms process higher quality litter more efficiently (Cotrufo et al. 2013), and as microbial residues make up a significant portion of SOC (Kallenbach et al. 2016), higher quality litters induce increased SOC formation, much of which is found in soil aggregates. Indeed, recent laboratory studies found an increased aggregate formation in the presence of microorganisms (Krause et al. 2019) and a relationship between litter quality and mineral-associated organic matter formation (Lavallee et al. 2018), but in situ research linking litter 
quality, microbial biomass (MB), and SOC dynamics is scarce.

In sandy soils which, due to lack of surface areas from clay and silt, have few mineral protection opportunities, aggregate formation may be crucial for maintaining SOC levels and to enable sustainable agriculture. In such a soil, Puttaso et al. (2013) could show that long-term application of medium-quality tamarind leaves led to almost double the amount of SOC stored compared to low-quality rice straw. The majority of this additional SOC was found in the aggregate fraction and was easily consumed by microbes upon aggregate destruction. They also found that treatments, which had highest amounts of MB (Puttaso et al. 2011), had the largest amounts of aggregates (Puttaso et al. 2013).

Yet, the mechanistic link between litter quality, microbial growth, aggregate formation, and the corresponding timescales needs to be explored in more detail, because Puttaso et al. (2013) only studied soil aggregates at a single point in time. The goal of this study was thus to make highly resolved repeated measurements to test a conceptual model of the temporal dynamics of aggregate formation. We hypothesized that in doing so, it would be possible to explain observed differences in aggregate formation by microbial processing efficiency (Fig. 1). We propose that microorganisms are actively driving aggregate formation through the following mechanisms: availability and quality of plant litter combined with favorable soil conditions, which in the studied experiment simultaneously occur in the beginning of the rainy season, facilitate different levels of microbial growth and excretion of binding agents. Higher microbial growth induces increased formation of soil aggregates, translating into higher amounts of SOC stabilized within the aggregates. The binding agents and aggregates persist longer than the microbial growth response; thus, transient microbial activity leads to significant SOC accumulation in aggregates over the long term. Within this conceptual model, SOC stabilized in aggregates is mostly explained by the quantity and turnover of microbes, which depends on the amount and quality of available litter, the quality influencing the ratio of microbial catabolism to anabolism, also termed carbon-use-efficiency (Cotrufo et al., 2013; Puttaso et al. 2011).

To test this conceptual model, we conducted repeated measurements in the 30 weeks following the application of contrasting quality litters. The study was conducted in an ongoing long-term bare fallow experiment in a tropical sandy soil in Thailand. Five different treatments were assessed: the unamended control, low-quality rice (Oryza sativa) straw (lqRS), low-quality dipterocarp (Dipterocarpus tuberculatus) leaf litter (lqDP), medium-quality tamarind (Tamarindus indica) leaf and petiole litter (mqTM), and high-quality groundnut (Arachis hypogaea) stover (hqGN). We followed the development of MB, dissolved fractions of

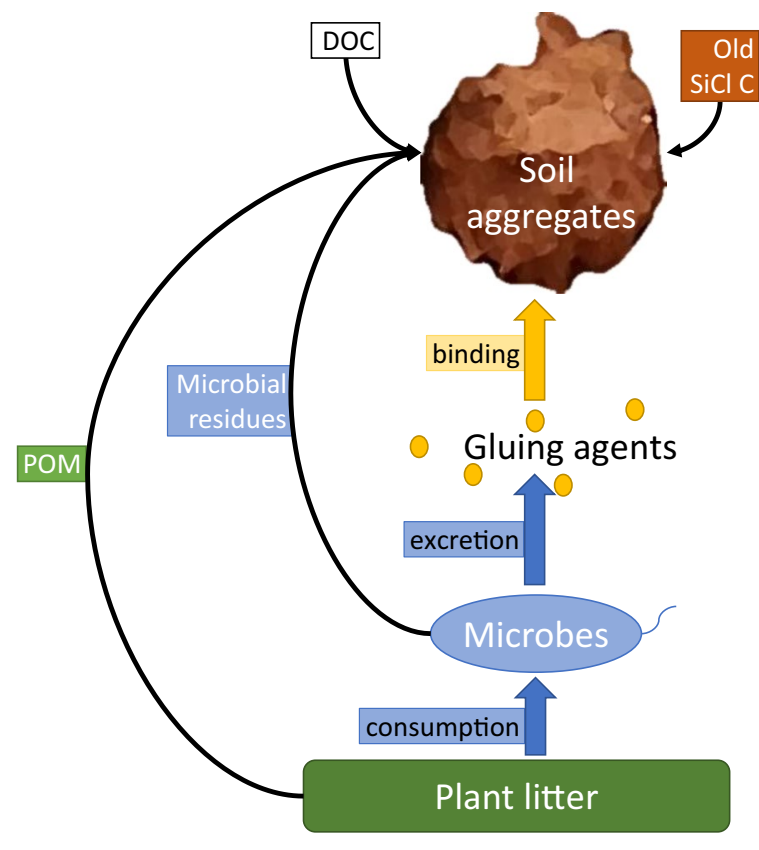

Fig. 1 Hypothesized conceptual model of microbially mediated aggregate formation. Microbes consume plant litter producing gluing agents that bind together soil aggregates and stabilize soil organic carbon (SOC) in aggregates. The SOC in aggregates may consist of particulate organic matter (POM), microbial residues, old silt and clay $(\mathrm{SiCl}) \mathrm{C}$, and dissolved organic carbon (DOC) attaching to parti-

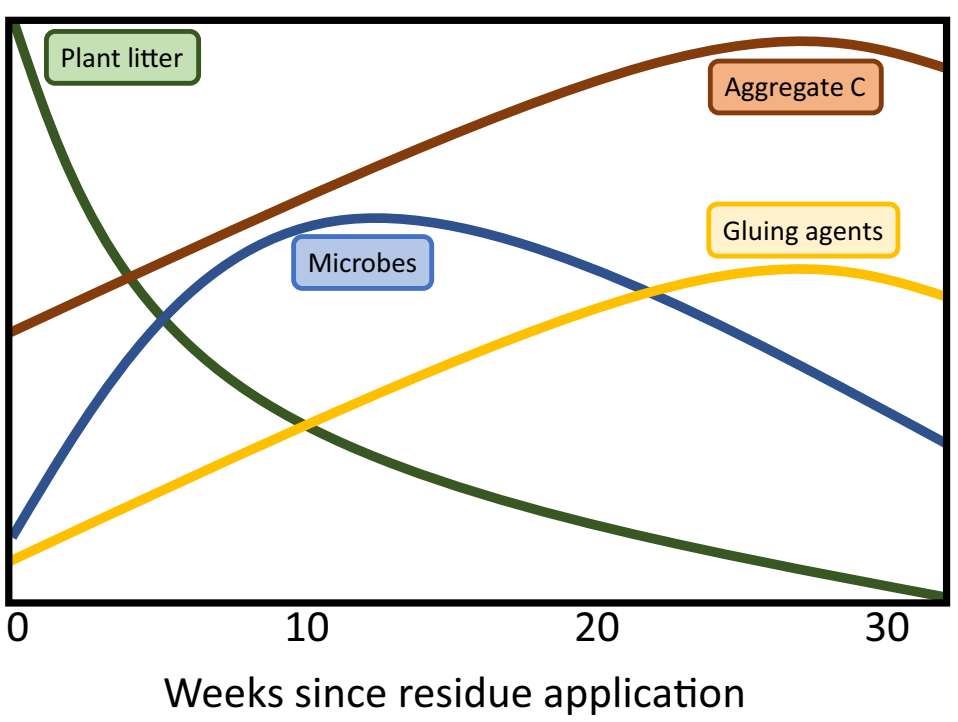

cle surfaces and SOC turnover is reduced inside aggregates. The gluing agents represent a conceptual link of microbial activity to aggregate formation but were not measured within this study. They are hypothesized to be more stable than the microbial growth response, thus leading to a longer term SOC stabilization in aggregates and a delayed peak in aggregates SOC compared to microbial biomass 
carbon and nitrogen, as well as bulk soil $\mathrm{C}$, aggregate $\mathrm{C}$, and aggregate weight to study their interlinkages and understand the timing of aggregate formation and disruption in situ.

The following hypotheses were tested:

a) Due to high temperature, favorable moisture conditions, and limited protection mechanisms in sandy soils, there is a high temporal dynamic of aggregate formation exhibiting as a significant temporal trend of aggregate weight and $\mathrm{C}$ content.

b) Aggregate formation follows the development of microorganisms, whose growth strongly depends on the litter quality. Thus, microbial growth is a significant explanatory variable for the development of aggregate SOC storage.

c) The formed aggregates are more persistent than microbial growth; thus, aggregate formation peaks after microbial biomass and the decline of aggregates is much slower than the reduction of microbial biomass.

\section{Material and Methods}

\subsection{Description of the Long-term Experiments' Study Site}

The assessed long-term field experiment was established on a degraded tropical sandy soil in 1995 , to study the potential of different quality litters to enhance SOC. It is located within the research station of the Office of Agriculture and Cooperatives of the Northeast, Khon Kaen province $\left(16^{\circ} 20^{\prime}\right.$ $\left.\mathrm{N} ; 102^{\circ} 49^{\prime} \mathrm{E}\right)$ in the northeast of Thailand. The soil is classified as Khorat sandy loam (Typic Kandiustult) with initial properties of $90 \%$ sand, $5 \%$ silt, and 5\% clay (Puttaso et al. 2013). Initial bulk density was described as $1.45 \mathrm{~g} \mathrm{~cm}^{-1}$, the $\mathrm{pH}$ value was 5.50 , and CEC $3.53 \mathrm{cmol} \mathrm{kg}^{-1}$ in the topsoil (0-15 cm depth; Vityakon et al. 2000). The climate is characterized as a savanna type with a distinct wet period from April to September and dry period from October to March (Fig. 2).

The experiment consists of five treatments with three replicates in a randomized block design of $4 \times 4 \mathrm{~m}^{2}$ plots. Plots receive yearly litter applications of $10 \mathrm{Mg} \mathrm{ha}^{-1}$ dry matter at the beginning of the rainy season. The experiment was historically designed with equal mass of residues, being representative of local farmers' field management reality. While treatments adding similar amounts of carbon would be scientifically preferable, it was decided to adhere to this historical design in this study. Important to note is that since the experiment was ongoing for 25 years, initial SOC levels in year 25 already differed significantly between treatments, up to a factor of two. In the evaluation year 25, in 2019, the litter was applied on the 2nd of May. Treatments were the unamended control (CT), rice (Oryza sativa) straw (lqRS), groundnut (Arachis hypogaea) stover (hqGN), tamarind (Tamarindus indica) litter (mqTM) with leaf and petiole litter at a ratio of 7:1 on a dry weight basis, and dipterocarp (Dipterocarpus tuberculatus) leaf litter (lqDP), all differing in chemical quality (Table 1). The litter was cut into pieces of 5-10 cm length (lqRS, hqGN) or $7-10 \mathrm{~cm}^{2}$ scraps (lqDP) before being distributed evenly on the plot surface and manually incorporated into the $20 \mathrm{~cm}$ topsoil using hoes. Plots were kept fallow by hand weeding upon need, approximately once per month in the rainy season and every second month in the dry season.

\subsection{Soil Sampling}

Soil sampling was conducted on the day before (week 0) and 2, 4, 8, 16, and 30 weeks after litter incorporation. Soil samples were collected with a soil auger in $0-15 \mathrm{~cm}$ depth from the inner $2 \times 2 \mathrm{~m}^{2}$ area at the center of the plots. They comprised a composite sample of 16 randomly collected subsamples. The samples were cooled, stored in plastic
Fig. 2 Climatic conditions as monthly rainfall (bars) and average temperature (dots with line) in 2019. Litter application was on the 2nd of May 2019. Data was recorded at Tha Phra Agrometeorological Station, Khon Kaen, Thailand

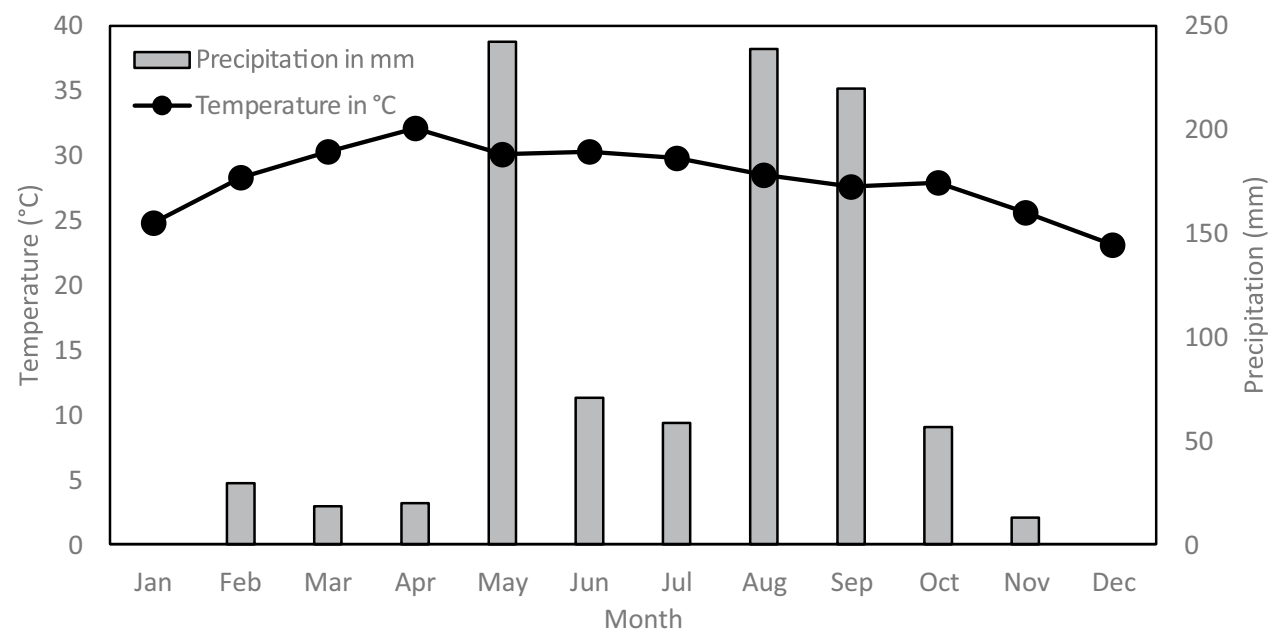


Table 1 Chemical characteristics of applied organic litter (Puttaso et al. 2013). Total $\mathrm{C}$ by Walkley and Black wet digestion; total $\mathrm{N}$ by micro-Kjeldahl; lignin and cellulose determined by acid detergent lignin method (Van Soest \& Wine 1968); polyphenols determined according to Anderson and Ingram (1993). Values within the same column that share the same capital letter are not significantly different $(p<0.05)$

\begin{tabular}{llllllll}
\hline Litter & Quality & $\mathrm{C}\left(\mathrm{g} \mathrm{kg}^{-1}\right)$ & $\mathrm{N}\left(\mathrm{g} \mathrm{kg}^{-1}\right)$ & $\mathrm{C} / \mathrm{N}$ & $\mathrm{L}\left(\mathrm{g} \mathrm{kg}^{-1}\right)$ & $\left.\mathrm{Pp}^{1} \mathrm{~g} \mathrm{~kg}^{-1}\right)$ & $\mathrm{Cellulose}^{\left(\mathrm{g} \mathrm{kg}^{-1}\right)}$ \\
\hline Rice straw & Low & $367^{\mathrm{A}}$ & $4.7^{\mathrm{A}}$ & $78^{\mathrm{A}}$ & $28.7^{\mathrm{A}}$ & $6.5^{\mathrm{A}}$ & $507^{\mathrm{A}}$ \\
Groundnut stover & High & $388^{\mathrm{A}}$ & $22.8^{\mathrm{B}}$ & $17^{\mathrm{B}}$ & $67.6^{\mathrm{A}}$ & $12.9^{\mathrm{A}}$ & $178^{\mathrm{AB}}$ \\
Dipterocarp & Low & $453^{\mathrm{B}}$ & $5.7^{\mathrm{A}}$ & $80^{\mathrm{A}}$ & $175.5^{\mathrm{B}}$ & $64.9^{\mathrm{B}}$ & $306^{\mathrm{AB}}$ \\
Tamarind & Medium & $427^{\mathrm{B}}$ & $13.6^{\mathrm{C}}$ & $32^{\mathrm{C}}$ & $87.7^{\mathrm{C}}$ & $31.5^{\mathrm{C}}$ & $143^{\mathrm{B}}$ \\
SE & & 7 & 0.8 & 3.4 & 19 & 5.6 & 46 \\
\hline
\end{tabular}

$C$, carbon; $N$, nitrogen; $L$, lignin; $P p$, polyphenols; $C / N$, carbon to nitrogen ratio; ${ }^{1}$ Palm et al. (2001); SE, standard error computed based on published measured values from different years (Vityakon et al. 2000; Samahadthai et al. 2010; Puttaso et al. 2013; Sanghaw et al. 2017)

bags, and taken to the laboratory for same day analysis of microbial $\mathrm{C}$ and $\mathrm{N}$. The soil remaining for fractionation was air-dried to constant weight and then stored in the dark until further analysis.

\subsection{Soil Fractionation}

\subsubsection{Wet Sieving}

Water stable aggregate size distribution was determined by wet sieving as proposed by Elliott (1986) with modifications as described below. Four size classes were determined (Fig. S1), which also included primary particles, such as sand grains, of the same size: large macroaggregates (LMA, $>2 \mathrm{~mm}$ ), small macroaggregates (SMA, $2-0.25 \mathrm{~mm}$ ), microaggregates (MiA, $0.25-0.053 \mathrm{~mm}$ ), and free particles of the silt and clay fraction $(\mathrm{SiCl},<0.053 \mathrm{~mm})$, not included in aggregates. An amount of $100 \mathrm{~g}$ air-dried soil, previously sieved through $8 \mathrm{~mm}$ mesh size, was used for the fractionation. Before the wet sieving, samples were rewetted to saturation by capillary rise and then gently transferred into the sieving apparatus (Daiki 2000, Daiki Rika Kogyo Co. Ltd.) with a nest of 2 sieves of the mesh sizes $2 \mathrm{~mm}$ and $0.25 \mathrm{~mm}$ which were submerged into water-filled tanks. To be comparable to earlier measurements in year 13 (Puttaso et al. 2013), the same sieving times were used. Hence, the sieves were vertically moved for $30 \mathrm{~min}$ at a range of $3.8 \mathrm{~cm}$ with 30 strokes per minute, while being submerged in water at all times. The suspension from the tank which passed through the $0.25-\mathrm{cm}$ sieve was further sieved by a sieve of $53 \mu \mathrm{m}$ mesh with 30 strokes per minute, $3.8 \mathrm{~cm}$ height and for $30 \mathrm{~min}$, with the intention that all aggregate fractions should be sieved for the same time (e.g., MiA fell through the sieves in the first sieving and did not have to withstand the same forces as SMA and MiA in that step). After sieving, the content of each sieve was gently transferred into a plastic container. Surplus water was carefully removed with a syringe and then samples were dried to constant weights at $50{ }^{\circ} \mathrm{C}$. The remaining suspension of water and soil $<0.053 \mathrm{~mm}$ was left to sediment for 4 days. Then, excessive water was removed by vacuum suction after which the samples were dried at $50^{\circ} \mathrm{C}$ to constant weights. The average recovery of soil material was $99.3 \%$ with the lowest value being $97.9 \%$.

\subsubsection{Density Fractionation}

The SMA and MiA fractions were separated from free particulate organic matter, employing a sodium polytungstate solution (SPT) of the density $1.6 \mathrm{~g} \mathrm{ml}^{-1}$ (Golchin et al. 1994; Puttaso et al., 2013). With amounts of less than $1 \mathrm{~g}$, the LMA fraction was considered too small for density fractionation. For the fractionation procedure, $10 \mathrm{~g}$ of sample, mixed with $35 \mathrm{ml} \mathrm{SPT}$, was gently shaken horizontally by hand for about 20 strokes and then left to settle for $1 \mathrm{~h}$. The manual shaking was repeated a second time followed by 20 -min centrifugation at $5600 \mathrm{~g}$ and $20^{\circ} \mathrm{C}$. A separation of the floating particulate organic matter from the remaining heavy fraction followed. Both fractions were thoroughly rinsed with tap water and then flushed twice with distilled water on a nylon tissue, to remove SPT, before being dried at $50{ }^{\circ} \mathrm{C}$.

\section{$2.4 \mathrm{C} / \mathrm{N}$ Analysis}

Analyses of carbon contents by dry combustion were conducted for bulk soil, the $\mathrm{SiCl}$ fraction, and the heavy fractions of SMA and MiA, employing a Multi N/C 2100S (Analytik Jena). Prior to analysis, the bulk soil was separated from visual organic compounds by hand picking. All samples were finely ground with a mortar before analysis. Initially measured C contents by the Multi N/C 2100S were significantly below contents of earlier years, which was found to be calibration error. Therefore, a recalibration and an upscaling of the data were performed, which is described in the Supplement in detail. 


\subsection{Microbial Biomass}

The microbial biomass $\mathrm{C}$ and $\mathrm{N}$ (MB C and MB N) contents were determined by chloroform fumigation-extraction (Amato and Ladd 1988). Fumigation samples were exposed to ethanol free chloroform for $24 \mathrm{~h}$ under a vacuum. For MB C and DOC determination, the $\mathrm{C}$ from both fumigated and unfumigated samples was extracted from $10 \mathrm{~g}$ of soil using $100 \mathrm{ml}$ of $0.5 \mathrm{M} \mathrm{K}_{2} \mathrm{SO}_{4}$ solution. A determination of C content by $\mathrm{K}_{2} \mathrm{Cr}_{2} \mathrm{O}_{7}$ wet digestion followed (Walkley \& Black 1934). For MB N and DON determination, extraction of fumigated and unfumigated samples was done with $100 \mathrm{ml}$ of $1 \mathrm{~N} \mathrm{KCl}$ from $10 \mathrm{~g}$ of soil, followed by a calorimetric measurement of ninhydrin-reactive $\mathrm{N}$ (Amato \& Ladd 1988). The values of MB C were calculated employing a $k_{\mathrm{EC}}$ value of 0.33 (Vance et al. 1987) and ninhydrinreactive $\mathrm{N}$ was converted to $\mathrm{MB} \mathrm{N}$ employing a factor of 3.1 (Amato \& Ladd 1988). Finally, all amounts of microbial C and $\mathrm{N}$ were adjusted to the dry matter base, correcting for measured water contents in the fresh samples by drying for $24 \mathrm{~h}$ at $105^{\circ} \mathrm{C}$.

\subsection{Statistical Analysis}

The statistical analysis was conducted using the GLIMMIX procedure of SAS version 9.4 (SAS Institute Inc., Cary, NC, USA). A mixed linear model accounted for the temporal autocorrelation of measurements within the same block and within the same plot (Piepho et al. 2004). The Akaike information criterion (AIC) indicated that the temporal autocorrelation was best represented by a Gaussian model. Transformations of response variables were used, where needed to assure normality and homogeneity of variance. The Shapiro-Wilk test assured normality of model residuals (the model for SMA C had the only significant derivation; $p<0.05)$. To test the posed hypotheses of a treatment effect with temporal interactions, type III tests of significance were used applying the Kenward-Roger estimation of degrees of freedom. Least square estimates of means and post hoc pairwise comparisons of means were done using the Tukey-Kramer method. Values reported throughout "Sect. 3" are the means estimated by the statistical model. Two types of statistical analyses were conducted. First, only the fixed effects of treatment, time, and the interaction of treatment $\times$ time were included, to assess which response variables had a significant change over time in different treatments. Also, a squared version of time (time ${ }^{2}$ ) was used to account for possible nonlinear temporal effect (e.g., initial increase followed by a decrease). In the second statistical model, other measured covariates such as DOC, MB N, and initial contents of $\mathrm{C}$ and $\mathrm{N}$ were added, to test which covariates could significantly explain the observed aggregation patterns, to determine their relative importance and to examine which of them could make the inclusion of a temporal effect obsolete. It was also tested whether the amount of $\mathrm{C}$ added by the different litter types would be a better explanatory variable for the $\mathrm{C}$ content of bulk soil and different fractions than a categorical treatment variable. This was done by comparing the AIC of the maximum likelihood fitted models using either a categorical treatment or the $\mathrm{C}$ content of the litter. Because of a higher AIC of the models using the amount of $\mathrm{C}$ added, the model with the categorical treatment variable was used (data not shown).

\section{Results}

\subsection{Temporal Development of Microbial Biomass}

Both MB C and MB N developed dynamically in all treatments (Figure S4), which within the statistical model, was best represented by a combination of a positive effect of time and a negative time ${ }^{2}$ effect (Table 2 (i) a). The treatment significantly affected MB C and MB N, but the absence of a significant interaction term between time and treatment suggested that MB C and MB N of different litter treatments developed at different levels but in parallel. In the following, all presented results refer to least square estimates of the statistical model. After the onset of the rainy season around week 0 , there was a rapid increase in both MB C and MB N, reaching a peak around week 8 to week 16 , followed by a rapid decline towards week 30 . The lqDP treatment had the lowest MB C values, starting at $45 \mathrm{mg} \mathrm{C} \mathrm{kg}^{-1}$, peaking at week 16 with $102 \mathrm{mg} \mathrm{C} \mathrm{kg}^{-1}$, then declining to $12 \mathrm{mg} \mathrm{C} \mathrm{kg}^{-1}$. The MB C of lqDP was significantly smaller than that of hqGN and mqTM, with an estimated difference of $39 \mathrm{mg} \mathrm{C} \mathrm{kg}^{-1}$ between lqDP and hqGN throughout the season (Table 2 (i) a). For MB N, the control (CT) had the lowest values, with an estimated peak at $14 \mathrm{mg} \mathrm{N} \mathrm{kg}^{-1}$ in week 16 with significantly higher values for lqDP ( $\left.20 \mathrm{mg} \mathrm{N} \mathrm{kg}^{-1}\right)$, lqRS and mqTM (28 and $30 \mathrm{mg} \mathrm{N} \mathrm{kg}^{-1}$ ), and hqGN (37 $\mathrm{mg} \mathrm{N} \mathrm{kg}^{-1}$ ).

When adding DOC and the bulk soil $\mathrm{N}$ content at week 0 as covariates, the importance of the temporal effects and the litter treatments on microbial parameters diminished, as indicated by a less significant $p$ value in all cases (Table 2 (i) b). For MB C, adding these measured covariates made the treatment effect non-significant $(p<0.1)$, indicating the importance of DOC in explaining the observed variation in MB $\mathrm{C}$, and to a lesser extent also MB N. Nevertheless, DOC and bulk soil $\mathrm{N}$ alone were not strong enough covariates to explain the temporal development of MB C and MB N. 


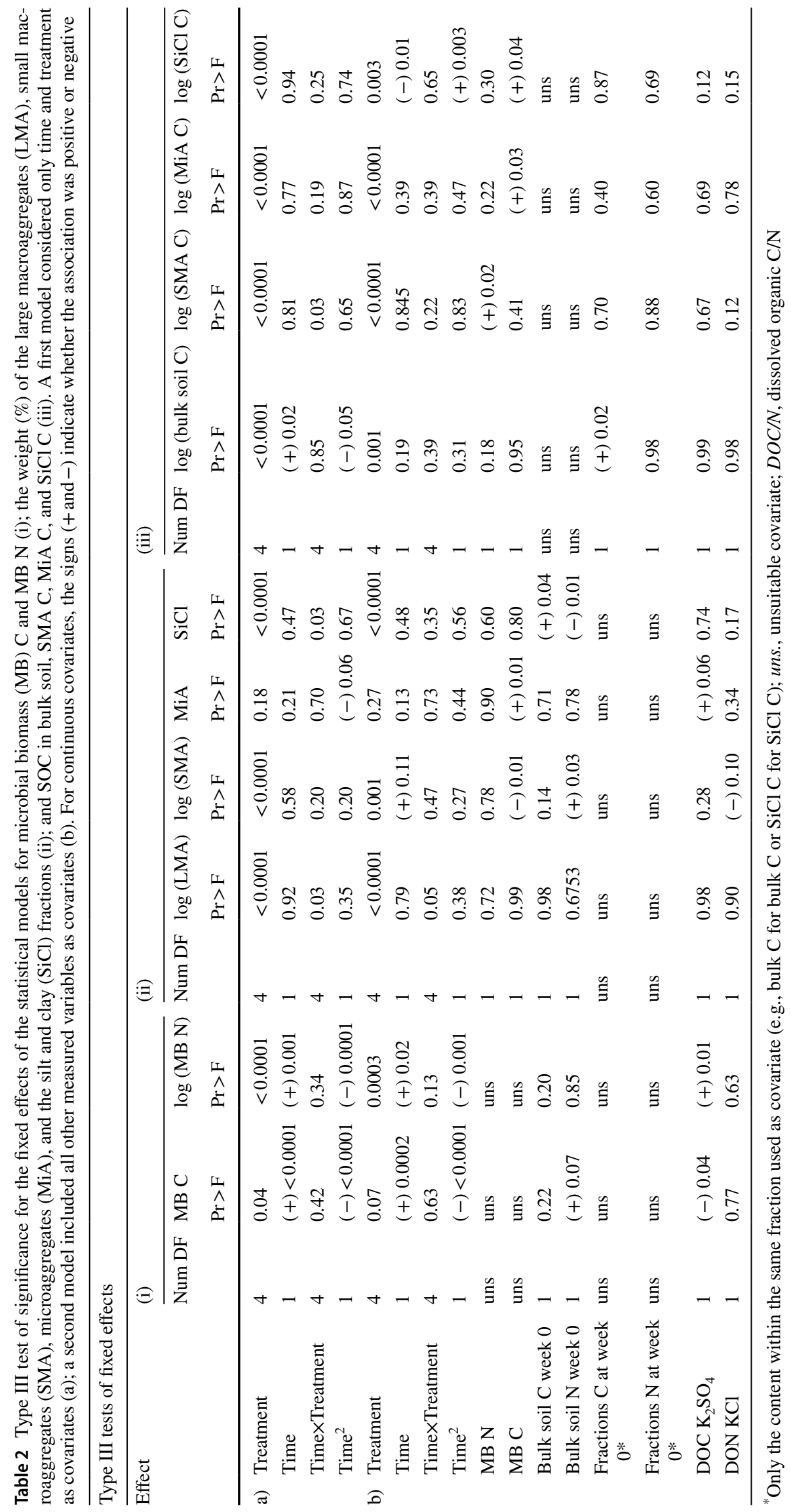




\subsection{Temporal Development of Aggregate Weights and Associated Variables}

A highly significant treatment effect existed for the weight distribution of all different aggregate fractions, except for MiA (Table 2 (ii) a). The MiA fraction was the largest, making up about $63 \%$ of the bulk soil (Table 3 ) but it had only a weak association with time ${ }^{2}(p<0.1)$. The weight of the $\mathrm{SiCl}$ and the LMA fraction had a significant treatment $\times$ time interaction. Thus, $\mathrm{SiCl}$ was higher in $\mathrm{CT}$ and lqDP (around $17 \%$ ) at week 0 compared to the other three treatments (around 15\%). This difference disappeared towards week 30, when all treatments contained around $15.5 \% \mathrm{SiCl}$ (Table 3). The CT treatment was lowest in SMA (18.7\%), significantly lower than hqGN (21.1\%), mqTM (20.3\%), and lqRS $(20.8 \%)$, but SMA showed no temporal effect. Additionally, lqDP (19.4\%) had significantly less SMA than hqGN and lqRS. For LMA, which made up less than $1 \%$ of weight, there was a significant interaction between treatment and time (Table 2 (ii) a). At week 0, CT, with only $0.1 \%$ of LMA weight, had significantly less LMA than all other treatments (up to $0.59 \%$ for mqTM). This significant difference only existed until week 16, while at week 30 the range of estimated means was 0.4 to $0.7 \%$ with no significant differences between treatments anymore (Table 3 ).

Adding covariates from other measurements within the second statistical model made the temporal effect non-significant for $\mathrm{MiA}$ and $\mathrm{SiCl}$ (Table 2 (ii) b). In this model, the weight of the $\mathrm{SiCl}$ fraction was only strongly associated with bulk soil $\mathrm{C}$ and $\mathrm{N}$ at week 0 (both $p<0.05$ ). For MiA, there was a significant $(p<0.01)$ positive association with MB C, and a weaker one $(p<0.1)$ with DOC (Table 2 (ii) b), which together eliminated the need for the time ${ }^{2}$ effect. For SMA, a significant negative association with MB C was found, but a positive association with bulk soil $\mathrm{N}$ at week 0 . For the weight of LMA, adding the measured covariates did not change the significance of the time interaction with treatment.

\subsection{Temporal Development of Aggregate C Content and Associated Variables}

All measured $\mathrm{C}$ contents, in bulk soil and measured fractions, were significantly $(p<0.0001)$ affected by the treatment (Table 2 (iii) a). However, only bulk soil C and SMA $\mathrm{C}$ showed a significant temporal trend in the first statistical model, which only assessed effects of time and treatment. Despite the lack of a significant temporal effect, all treatments except hqGN and mqTM differed significantly from one another in $\mathrm{C}$ stored in the $\mathrm{SiCl}$ fraction. With $1067 \mathrm{mg}$ $\mathrm{C} \mathrm{kg}^{-1}$ bulk soil at the start of the experiment, the CT treatment had the lowest amounts of $\mathrm{SiCl} \mathrm{C}$, while hqGN, with $1525 \mathrm{mg} \mathrm{C} \mathrm{kg}^{-1}$ bulk soil, and mqTM with $1654 \mathrm{mg} \mathrm{C} \mathrm{kg}^{-1}$ bulk soil had the highest one (Table 3; Fig. 3). A similar proportion of bulk soil $\mathrm{C}$ was found in $\mathrm{MiA}$ and $\mathrm{SiCl}$, but $\mathrm{SiCl}$ made up less than $20 \%$ of weight compared to more than $60 \%$ of the MiA fraction. The amount of $\mathrm{C}$ stored in the MiA fraction was again lowest in CT (960 $\mathrm{mg} \mathrm{C} \mathrm{kg}^{-1}$ bulk soil) and highest in hqGN and mqTM (1446 and $1466 \mathrm{mg}$ $\mathrm{C} \mathrm{kg}^{-1}$ bulk soil, respectively). Of all measured $\mathrm{C}$ fractions, the lowest share of the total bulk soil $\mathrm{C}$ was found in SMA $\mathrm{C}$ (Table 3), yet SMA C had a distinct temporal dynamic for different treatments (Table 2 (iii) a). At the beginning, SMA $\mathrm{C}$ in CT (255 mg C kg-1 bulk soil) was significantly lower than SMA C of all other treatments (on average $406 \mathrm{mg} \mathrm{C}$ $\mathrm{kg}^{-1}$ bulk soil). However, different temporal developments of treatments during the season led to a gain in SMA C in CT, hqGN, and mqTM with time, while lqDP and lqRS experienced a loss. This contrasting temporal trends led to less differentiation of SMA C between treatments in week 30 , where CT (280 $\mathrm{mg} \mathrm{C} \mathrm{kg}^{-1}$ bulk soil) was only significantly different from hqGN and mqTM (both around $450 \mathrm{mg}$ $\mathrm{C} \mathrm{kg}^{-1}$ bulk soil), but not from lqDP and lqRS (Table 3 ).

Due to the very low weight of the isolated LMA fraction (on average about $0.4 \mathrm{~g}$ ), a density fractionation was not possible, and thus, the $\mathrm{C}$ content of this fraction could not be measured in this study. However, there was a significant correlation $(p<0.0001)$ between the least square means of the weight of LMA and the missing amount of bulk soil $\mathrm{C}$ in the measured fractions (bulk soil $\mathrm{C}$ minus all fractions $\mathrm{C}$; Fig. 4), suggesting that the LMA fraction may contain about $15 \%$ of $\mathrm{C}$ on average.

The bulk soil $\mathrm{C}$ was subject to a significant time, time ${ }^{2}$, and treatment effect but lacking an interaction with time (Table 2 (iii) a), suggesting again a parallel development of the treatments at different levels, increasing after litter addition until week 16 , followed by a decrease towards week 30 (Table 3). Overall, CT had the lowest amounts of bulk soil C (2541 $\mathrm{mg} \mathrm{C} \mathrm{kg}^{-1}$ at week 30). Medium amounts were found in lqDP and lqRS, while hqGN and mqTM had significantly higher bulk soil $\mathrm{C}$ than all other treatments (4923 $\mathrm{mg} \mathrm{C} \mathrm{kg}^{-1}$ bulk soil at week 30 ).

Including the covariates from other measurements in the second statistical model made the temporal effect insignificant for bulk soil C and SMA C (Table 2 (iii) b). When adding the bulk soil $\mathrm{C}$ content of week 0 as covariate, only the treatment remained a significant covariate for bulk soil $\mathrm{C}$. All significant associations that $\mathrm{MB} \mathrm{C}$ and $\mathrm{MB} \mathrm{N}$ had with $\mathrm{C}$ contents of different fractions were positive. For SMA $\mathrm{C}$, adding $\mathrm{MB} \mathrm{N}$ as covariate $(p<0.05)$ made the temporal effect redundant. For MiA C, MB C was a significant covariate $(p<0.05)$, but not eliminating the need for treatment as covariate. For $\mathrm{SiCl} \mathrm{C}$, the $\mathrm{MB} \mathrm{C}$ was a significant covariate $(p<0.05)$ reducing the importance of the treatment (from $p<0.0001$ to $p<0.01$ ), but interestingly adding a significant time and time ${ }^{2}$ effect to explain the remaining variance. 






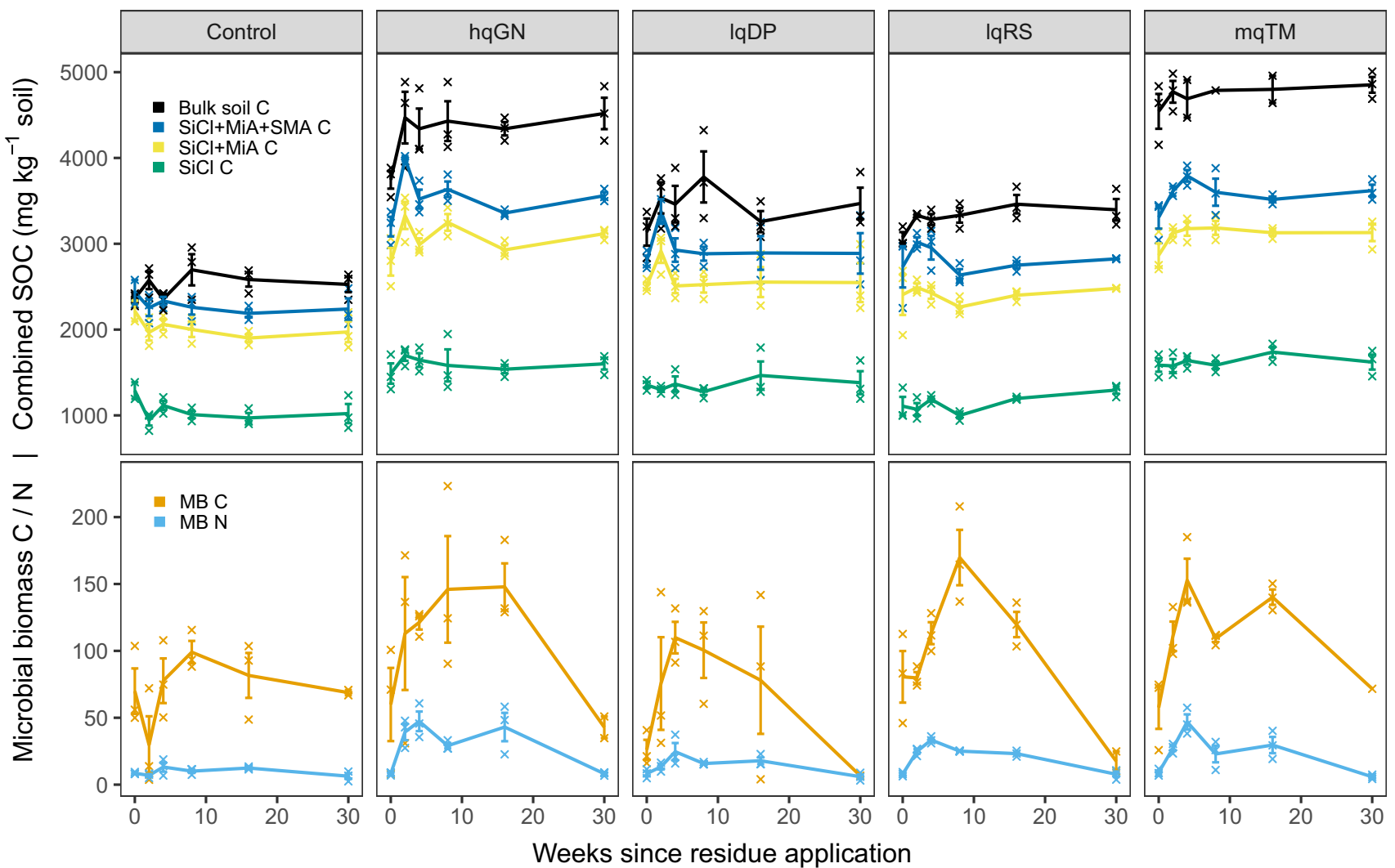

Fig. 3 Soil organic carbon (SOC) in bulk soil, the different soil fractions of silt and clay $(\mathrm{SiCl})$, microaggregates $(\mathrm{MiA})$ and small macroaggregates (SMA) in combination and microbial biomass (MB) $\mathrm{C}$ and MB N. Presented is the raw data, the lines connect arithmetic means at each time of measurement, and error bars represent plus and minus the standard error $(n=3)$. From bottom to top: MB $\mathrm{N}$ (light blue), $\mathrm{MB} \mathrm{C}$ (orange), $\mathrm{SOC}$ in $\mathrm{SiCl}$ (dark green), $\mathrm{SiCl}+\mathrm{MiA}$ (light green), $\mathrm{SiCl}+\mathrm{MiA}+\mathrm{SMA}$ (dark blue) and bulk soil (black). The reader is referred to the supplement for individual graphs of $\mathrm{MB} C$ and MB N (Fig. S4) alone and the $\mathrm{C}$ content of individual fractions (Fig. S5)

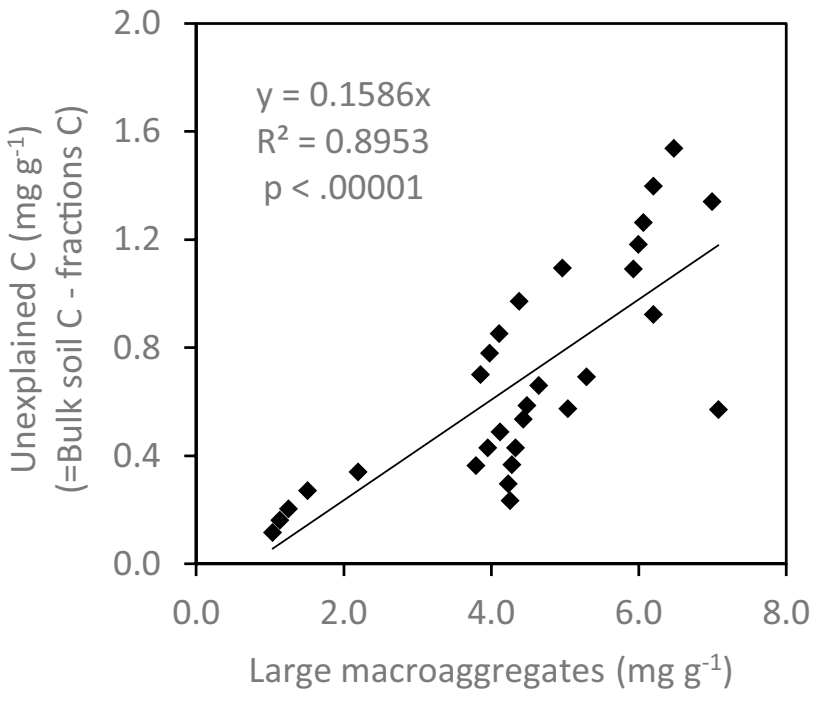

Fig. 4 Correlation between unexplained $\mathrm{C}$ and weight of large macroaggregates (LMA). Displayed are the least square means of both

\section{Discussion}

The results showed a high importance of the litter quality for the weight and $\mathrm{C}$ contents of several size fractions at the start of measurements. The highest amounts of $\mathrm{C}$ under mqTM, followed by hqGN in all soil fractions, were in alignment with earlier studies (Puttaso et al. 2013) and to be expected after 25 years of residue application. Yet, this study provides additional insights into the mechanisms through the temporal development of aggregates and the importance that MB thereby plays. The significant associations of MB $\mathrm{C}$ with the weight of MiA (positive) and SMA (negative), and additionally positive associations of MB $\mathrm{N}$ with SMA $\mathrm{C}$ and $\mathrm{MB} \mathrm{C}$ with MiA C and $\mathrm{SiCl} \mathrm{C} \mathrm{(Table} 2$ b), corroborate the hypothesized direct contribution of microbial activity to aggregate formation. Aggregate dynamics appeared as increased weight fractions in LMA with corresponding reduced weight fractions in $\mathrm{SiCl}$, while stabilization of new $\mathrm{C}$ showed in the SMA and bulk soil. The clear differences between litter quality treatments in amounts of $\mathrm{MB}$, for 
example, by a factor of up to 1.5 between lqDP and hqGN in $\mathrm{MB} \mathrm{C}$, demonstrate the positive effect of high-quality litter to promote MB. The importance of increased MB for increased aggregate formation showed in the dynamics of $\mathrm{MiA}$ weights, where adding MB $\mathrm{C}$ as covariate eliminated the need for a temporal effect to explain the observed variation in the data (Table 2 a vs b). Even after a duration of 25 years, there is a dynamic SOC development in this long-term experiment. Temporal gains of SOC (bulk soil $\mathrm{C}$ and SMA C) or losses (SMA C in lqDP and lqRS) were detectable and significant (Table 3). Earlier studies in the same experiment (Puttaso et al. 2013; Kunlanit et al. 2014) already showed that litter quality and not quantity led to differences in bulk soil $\mathrm{C}$ and in aggregate stored $\mathrm{C}$. These results were corroborated in this study: the lqDP treatment, containing the highest amount of $\mathrm{C}$ in litter, was significantly lower in bulk soil $\mathrm{C}$ than hqGN and mqTM, while different $\mathrm{C}$ contents in litter were a less suitable explanatory variable for bulk soil and fraction $\mathrm{C}$ contents than the categorical treatment variables. It was shown before that the contrasting litter qualities are processed with different efficiencies, facilitating distinct amounts of MB (Puttaso et al. 2011). The connections between $\mathrm{MB}$ and soil $\mathrm{C}$ fractions found in this study (Table 2 (iii) b) further suggest that more MB directly facilitates increased amounts of aggregates and $\mathrm{C}$ stored therein. This provides further evidence that the efficiency of microbial litter processing ultimately determines how much aggregation can be achieved per amount of carbon processed (Lavallee et al. 2018). Soil aggregation and the microbial community can explain more than $90 \%$ of litter C retention in soils (Zhang et al. 2019). Both were also closely linked in this study, where the amount of MB N was a significant explanatory covariate for SMA C (Table 2 (iii) b), usually the most dynamic $\mathrm{C}$ fraction (Six et al. 2000). Even for the $\mathrm{C}$ content of $\mathrm{MiA}$ and $\mathrm{SiCl}$ fractions, which did not show a significant temporal trend in the initial statistical model, MB $\mathrm{C}$ was a highly significant covariate. Hence, while so far, the connection of $\mathrm{MB}$ and aggregation across time was proven under controlled lab conditions (Krause et al. 2019; Bucka et al. 2019), this study showed the relevance of the temporal development pattern of MB for explaining temporal dynamics observed in aggregates and thus $\mathrm{C}$ storage in the field.

While initial $\mathrm{C}$ content was a significant covariate explaining observed $\mathrm{C}$ contents across time for bulk soil, none of the initial $\mathrm{C}$ content of individual fractions could explain their temporal development (Table 2 (iii) b). Hence, fractions were more dynamic than bulk soil, i.e., $\mathrm{SiCl}$ particles shifting between fractions due to aggregate formation and disruption, a dynamic also observed in tracer studies (De Gryze et al. 2006). Thus, when the amount of aggregates increase after litter addition, as observed for LMA and suggested by increasing amounts of SMA $\mathrm{C}$ for hqGN and mqTM, more $\mathrm{C}$ found in aggregates could partly originate from $\mathrm{SiCl} \mathrm{C}$, moved upwards in the aggregate hierarchy (Tisdall and Oades 1982) to form aggregate sizes of MiA or SMA. Temporal dynamics were seen in both, the $\mathrm{C}$ contents of the fractions and in their weight, but the LMA and MiA weights fraction were more dynamic than SMA, potentially related to sand of the same size class (SMA 99\% on average, MiA $96.7 \%$ on average at time 0 ; Fig. S3). Hence, the potential shifts of the $\mathrm{SiCl}$ fraction between size classes during aggregate formation and disruption should be considered when interpreting the storage of $\mathrm{C}$ in different aggregate size classes. This consideration shows the relevance of being able to distinguish between operationally defined soil $\mathrm{C}$ fractions such as particulate organic matter in or outside aggregates or $\mathrm{C}$ in $\mathrm{SiCl}$.

While about $50 \%$ of the bulk soil $\mathrm{C}$ in the examined soil was stored in aggregates (results of this study and of Puttaso et al., 2013), increased C due to higher quality litter was also found in free $\mathrm{SiCl}$. Litter quality-related differences in $\mathrm{SiCl} \mathrm{C}$ suggest that the idea of an absolute saturation of the $\mathrm{SiCl}$ fraction (Hassink 1997) may be an oversimplification. For example, although CT had a higher weight of the $\mathrm{SiCl}$ fraction compared to mqTM (17.4 vs $15.2 \%$ ), mqTM stored $55 \%$ more $\mathrm{C}$ in this free $\mathrm{SiCl}$ (Table 3). In fact, recent studies show that despite the $\mathrm{SiCl}$ content being a good predictor for C storage potential (Cotrufo et al. 2019), high-quality litter can lead to higher levels of $\mathrm{C}$ stored in $\mathrm{SiCl}$ (Lavallee et al. 2018). It was found that MB has the ability to attach to new spots onto the $\mathrm{SiCl}$ fraction, where no $\mathrm{C}$ was priorly attached, thus effectively creating new patches of $\mathrm{C}$ on free surface areas (Kopittke et al. 2018, 2020). This mechanism would suggest that the higher amounts of $\mathrm{SiCl} \mathrm{C}$ in mqTM and hqGN treatments compared to other litter treatments were a result of higher carbon use efficiencies (Puttaso et al. 2011; Cotrufo et al. 2013; Lavallee et al. 2018). The significant differences in $\mathrm{SiCl} \mathrm{C}$ between low-quality (lqRS, lqDP) and medium- or high-quality litter (hqGN, mqTM) treatments must thus be a long-term result of different carbon use efficiencies rather than the amount of $\mathrm{C}$ applied by litter, which was highest in lqDP (Table 1). An interesting question is in what form new $\mathrm{C}$ is attached to $\mathrm{SiCl}$. Attached microbial cell walls remaining after microbial death could be a potential pathway and the positive associations of MB with $\mathrm{C}$ of all fractions would suggest so. Yet, Angst et al. (2021) recently suggested that sorption of DOC to particles could be of equal importance. For example, low molecular weight DOC contributed to increased levels of bulk soil $\mathrm{C}$ at lower depths through leaching in the same long-term experiment as used in this study (Kunlanit et al. 2020). However, our findings cannot distinguish if transferred DOC is primarily attached to $\mathrm{SiCl}$ in the form of microbially synthesized products by the microbes feeding on the DOC, or whether 
microbially depolymerized $\mathrm{DOC}$ attaches directly to $\mathrm{SiCl}$ surfaces without further microbial interaction.

The high amounts of free $\mathrm{SiCl} \mathrm{C}$ that were isolated by the fractionation (Table 3 ) raise the question if the treatment differences in bulk soil $\mathrm{C}$ should really be mostly attributed to aggregate formation. While the majority of additional $\mathrm{C}$ of high-quality compared to low-quality litter is found within aggregates, higher $\mathrm{C}$ stored in aggregates could also be due to a higher $\mathrm{C}$ content of the $\mathrm{SiCl}$ building blocks. While we have not destroyed aggregates to separate the POM and $\mathrm{SiCl}$ therein, it is likely that the increasing ratios of mqTM-C to CT-C in various soil fractions, i.e., in $\mathrm{SiCl}$ (1.55), MiA (1.53) and SMA (1.7) at time 0 , are in fact a combination of a higher number of aggregates formed from particulate organic matter (POM) and $\mathrm{SiCl}$ building blocks which are also higher in $\mathrm{C}$ (for the ratios of hqGN C to CT C, they were 1.43, 1.51, and 1.64 for $\mathrm{SiCl}, \mathrm{MiA}$, and SMA, respectively). Given that the ratio of $\mathrm{C}$ in mqTM to CT is similar in MiA (1.53) and $\mathrm{SiCl}(1.55)$, it is likely that there is little intra-aggregate $\mathrm{POM}$ in MiA, as the additional POM should increase this ratio. In contrast, the higher ratio of 1.7 in the SMA fraction supports the idea of additional POM in that fraction. As $\mathrm{SiCl}$ and $\mathrm{MiA}$ combined stored between 67 (mqTM) and $83 \%(\mathrm{CT})$ of bulk soil C, the estimated low POM content in MiA could mean that the majority of $\mathrm{C}$ is associated with $\mathrm{SiCl}$, found both, in and outside of aggregates. Even if the overall contribution of POM to soil $\mathrm{C}$ seems low and most $\mathrm{C}$ was found in the $\mathrm{SiCl}$ fraction, aggregates may be relevant for the formation of new $\mathrm{C}$ because of the favorable microhabitat they provide (Krause et al. 2019). Possibly, the protection from drought or predators that microorganisms experience inside aggregates (Six et al. 2000) also contributes towards a more efficient formation of new $\mathrm{SiCl} \mathrm{C}$ inside of aggregates.

The higher $\mathrm{C}$ storage due to high-quality litter addition, found in all fractions, suggests multiple pathways to store new C. Macroaggregate formation around POM (Six et al. $2000,2004)$ may be happening at the same time as microaggregate formation outside of macroaggregates by microbes feeding on DOC (Bucka et al. 2019) and attachment of new $\mathrm{C}$ to $\mathrm{SiCl}$ surfaces by microbial processing of $\mathrm{N}$-rich litter (Kopittke et al. 2018, 2020). This suggest that conceptual, as well as numerical models of $\mathrm{C}$ storage and aggregate formation (e.g., Millenial model, Abramoff et al. 2018), should aim to consider these processes simultaneously, and ideally track the form in which $\mathrm{C}$ is stored within different fractions (e.g., whether aggregate $\mathrm{C}$ consists mainly of POM or $\mathrm{SiCl} \mathrm{C)}$. The presented evidence for the importance of microorganisms and microbial carbon use efficiency in the stabilization of $\mathrm{C}$ in all size fractions (Table $2 \mathrm{~b}$ ) should be translated into conceptual and numeric models of aggregate formation. This has so far only indirectly been realized (e.g., by a microbial activity factor; Segoli et al. 2013) or mostly ignored (Abramoff et al. 2018), and thus, considering microbial activity as a driving factor of aggregate formation models, promises to be a significant model improvement.

Despite MB C and MB N being crucial in explaining aggregate weight distributions and $\mathrm{C}$ in all fractions, newly stabilized carbon outlasted MB C and MB N. For example, while the amount of MB C and MB N reduced drastically after week 16 in all treatments, SMA C of mqTM, hqGN, and CT treatments kept increasing until the end of the experiment (Table 3). Bulk soil $\mathrm{C}$ also had its estimated peak in week 16 , but its decline thereafter was much slower than that of MB C: bulk soil C contents of week 30 were comparable to week 8 and MB contents of week 30 were comparable to week 0 . This supports the initial hypothesis that newly stabilized $\mathrm{C}$ outlasts the MB lifecycle. The time lag between aggregate $\mathrm{C}$ formation and loss of aggregate $\mathrm{C}$ should thus lead to a slightly positive $\mathrm{C}$ balance for hqGN and mqTM at the end of each season. One could argue that their observed $\mathrm{C}$ accumulations over the years were thus a cumulative result of small annual increases. On the other hand, additional aggregates formed through annual supply of plant material are likely to also protect $\mathrm{C}$ of previous years. Thus, the persistence of $\mathrm{C}$ would not just depend on the turnover time of different carbon fractions but also on the supply of new plant material to promote MB, supporting the formation of aggregates which provide additional protection. This additional protection by aggregates was shown in earlier work, conducted in year 13 within the same experiment: crushed aggregates released up to $19 \%$ of their $\mathrm{C}$ content as $\mathrm{CO}_{2}$ within 42 days of incubation while crushed $\mathrm{SiCl}$ only released 3\% (Puttaso et al. 2013).

It has been proposed earlier that low-quality organic inputs are driving long-term SOM build-up, as summarized, e.g., by Palm et al. (2001). However, the results of this study rather support the recent paradigm shift suggesting that lowquality organic inputs mainly increase POM, which is only stable in the medium term. In contrast, high-quality organic inputs led to sequestration of more stable $\mathrm{SiCl} \mathrm{C}$ through the microbial pathway (e.g., Cotrufo et al. 2013). Kunlanit et al. (2014) suggested that the reason why intermediate-quality litter, such as mqTM, led to highest levels of SOC, was due to the combination of a regulatory $\mathrm{N}$ effect, facilitating strong MB growth, and a lower leaching of decompositionderived substances compared to hqGN. The slower decomposition of mqTM was attributed to a moderately higher lignin and polyphenol content. Yet, our study provides an additional explanation: if MB driven aggregate formation is an essential component of SOC protection, slower decomposing mqTM litter may maintain aggregates for a longer time than hqGN, thereby also slowing the decomposition of all $\mathrm{C}$ stored within the aggregates. Therefore, the highest levels of bulk soil SOC found in mqTM could also be 
a result of the feature of mqTM to support aggregates for a longer time, when other litter types are already decomposed. Higher $\mathrm{N}$ use efficiency and aggregate formation of mqTM are likely a result of a better synchrony between the need of microbes for $\mathrm{C}$ and $\mathrm{N}$ (Palm et al. 2001) in mqTM compared to hqGN. For hqGN, $80 \%$ of litter is decomposed within the first 4 weeks compared to only $50 \%$ for mqTM (Puttaso et al. 2011). Overall, the results give an insight into the relevance of the timing of litter addition, aggregate formation, and aggregate degradation for long-term SOC sequestration. A better understanding of how litter $\mathrm{C}$ moves through the different stages of stabilization as either POM, DOC, or microbial residue in different fractions could be facilitated by isotopic tracers. Combined with numerical models of aggregate formation, this could help to better understand the timescales at which new aggregate $\mathrm{C}$ is formed and lost, once the litter is fully decomposed.

\section{Conclusions}

Our study provided strong evidence of the importance of $\mathrm{MB}$ in the formation of aggregates under field conditions. Differences in aggregate stored $\mathrm{C}$ were connected to differences in MB growth and utilization efficiency due to different litter qualities, with mqTM and hqGN litter having most aggregate $\mathrm{C}$ and $\mathrm{MB}$. All fractions and especially the $\mathrm{SiCl}$ fraction were gaining $\mathrm{C}$ from medium- and high-quality litter. The temporal developments of aggregate weights and $\mathrm{C}$ content were strongly connected to $\mathrm{MB}$, and $\mathrm{C}$ contents positively associated to $\mathrm{MB}$, showing the importance of $\mathrm{MB}$ for aggregate formation in the field. Yet, $\mathrm{SiCl} \mathrm{C}$ was likely the fraction that contributed most strongly to aggregate $\mathrm{C}$, even in the studied sandy soil. Future research on the connection between MB and aggregate formation should thus focus on the form the aggregate $\mathrm{C}$ is stabilized. Interaggregate particulate organic matter could be lost relatively fast after aggregate breakup whereas new $\mathrm{SiCl} \mathrm{C}$ generated through microbial processing could lead to prolonged $\mathrm{C}$ accumulation. Applying isotopically labeled litter could help to disentangle how fast interaggregate particulate organic matter becomes $\mathrm{SiCl} \mathrm{C}$, and if newly generated $\mathrm{SiCl} \mathrm{C}$ (such as from mqTM and hqGN) has the same slow turnover as $\mathrm{SiCl}$ has in general. If this would be the case, N-rich litter and their efficient processing could be the key to increase soil fertility in the long-term and for $\mathrm{C}$ sequestration attempts in the context of climate smart agriculture.

Supplementary Information The online version contains supplementary material available at https://doi.org/10.1007/s42729-021-00696-6.
Author Contribution PV and GC designed the long-term experiment. It is maintained by the group of PV. ML designed the research of this study. SSch conducted most of the field and lab work together with ML. ML wrote and designed the initial manuscript draft together with SSch. All co-authors contributed in developing the final manuscript.

Funding Open Access funding enabled and organized by Projekt DEAL. Samuel Schlichenmeier's field trip was supported by the Dr. Hermann Eiselen Scholarship Program of the foundation fiat panis (http://www.stiftung-fiat-panis.de/en/research-funding/master-progr amm). Moritz Laub's stay in Thailand was financially supported by the Royal Golden Jubilee (RGJ) program under the Thailand Research Fund (TRF) grant number PHD/0157/2556 and TRF-DAAD Project Based Personnel Exchange Program (PPP) 2018-2020.

Data Availability The data can be made available from the corresponding author upon request.

Code Availability Not applicable.

\section{Declarations}

Conflict of Interest The authors declare no competing interests.

Open Access This article is licensed under a Creative Commons Attribution 4.0 International License, which permits use, sharing, adaptation, distribution and reproduction in any medium or format, as long as you give appropriate credit to the original author(s) and the source, provide a link to the Creative Commons licence, and indicate if changes were made. The images or other third party material in this article are included in the article's Creative Commons licence, unless indicated otherwise in a credit line to the material. If material is not included in the article's Creative Commons licence and your intended use is not permitted by statutory regulation or exceeds the permitted use, you will need to obtain permission directly from the copyright holder. To view a copy of this licence, visit http://creativecommons.org/licenses/by/4.0/.

\section{References}

Abramoff R, Xu X, Hartman M et al (2018) The millennial model: in search of measurable pools and transformations for modeling soil carbon in the new century. Biogeochemistry 137:51-71. https://doi.org/10.1007/s10533-017-0409-7

Amato M, Ladd JN (1988) Assay for microbial biomass based on ninhydrin-reactive nitrogen in extracts of fumigated soils. Soil Biol Biochem. https://doi.org/10.1016/0038-0717(88)90134-4

Anderson JM, Ingram JSI (1993) Tropical Soil Biology and Fertility: A Handbook of Methods., Second Edi. CAB international, Wallingford

Angst G, Mueller KE, Nierop KGJ, Simpson MJ (2021) Plant- or microbial-derived? A review on the molecular composition of stabilized soil organic matter. Soil Biol Biochem 156:108189. https://doi.org/10.1016/j.soilbio.2021.108189

Bucka FB, Kölbl A, Uteau D et al (2019) Organic matter input determines structure development and aggregate formation in artificial soils. Geoderma 354:113881. https://doi.org/10.1016/j. geoderma.2019.113881 
Chenu C, Cosentino D (2011) Microbial regulation of soil structural dynamics. The architecture and biology of soils: life in inner space. CABI, Wallingford, pp 37-70

Cotrufo MF, Ranalli MG, Haddix ML et al (2019) Soil carbon storage informed by particulate and mineral-associated organic matter. Nat Geosci 12:989-994. https://doi.org/10.1038/ s41561-019-0484-6

Cotrufo MF, Wallenstein MD, Boot CM et al (2013) The Microbial Efficiency-Matrix Stabilization (MEMS) framework integrates plant litter decomposition with soil organic matter stabilization: do labile plant inputs form stable soil organic matter? Glob Chang Biol 19:988-995. https://doi.org/10.1111/gcb.12113

De Gryze S, Six J, Merckx R (2006) Quantifying water-stable soil aggregate turnover and its implication for soil organic matter dynamics in a model study. Eur J Soil Sci. https://doi.org/10. $1111 / \mathrm{j} .1365-2389.2005 .00760 . \mathrm{x}$

Elliott ET (1986) Aggregate structure and carbon, nitrogen, and phosphorus in native and cultivated soils. Soil Sci Soc Am J 50:627-633. https://doi.org/10.2136/sssaj1986.0361599500 $5000030017 \mathrm{x}$

Golchin A, Oades JM, Skjemstad JO, Clarke P (1994) Study of free and occluded particulate organic matter in soils by solid state $13 \mathrm{C}$ Cp/MAS NMR spectroscopy and scanning electron microscopy. Aust J Soil Res 32:285-309. https://doi.org/10.1071/SR9940285

Hassink J (1997) The capacity of soils to preserve organic C and $\mathrm{N}$ by their association with clay and silt particles. Plant Soil 191:77-87. https://doi.org/10.1023/A:1004213929699

Kallenbach CM, Frey SD, Grandy AS (2016) Direct evidence for microbial-derived soil organic matter formation and its ecophysiological controls. Nat Commun 7:1-10. https://doi.org/10.1038/ ncomms 13630

Kopittke PM, Dalal RC, Hoeschen C et al (2020) Soil organic matter is stabilized by organo-mineral associations through two key processes: the role of the carbon to nitrogen ratio. Geoderma 357:113974. https://doi.org/10.1016/j.geoderma.2019.113974

Kopittke PM, Hernandez-Soriano MC, Dalal RC et al (2018) Nitrogenrich microbial products provide new organo-mineral associations for the stabilization of soil organic matter. Glob Chang Biol 24:1762-1770. https://doi.org/10.1111/gcb.14009

Krause L, Biesgen D, Treder A et al (2019) Initial microaggregate formation: association of microorganisms to montmorillonitegoethite aggregates under wetting and drying cycles. Geoderma 351:250-260. https://doi.org/10.1016/j.geoderma.2019.05.001

Kunlanit B, Rasche F, Puttaso A et al (2020) Vertical dynamics of dissolved organic carbon in relation to organic input quality and microaggregate formation in a coarse- textured Ultisol. Eur J Soil Sci 71:459-471. https://doi.org/10.1111/ejss.12874

Kunlanit B, Vityakon P, Puttaso A et al (2014) Mechanisms controlling soil organic carbon composition pertaining to microbial decomposition of biochemically contrasting organic residues: evidence from midDRIFTS peak area analysis. Soil Biol Biochem 76:100108. https://doi.org/10.1016/j.soilbio.2014.05.006

Lavallee JM, Conant RT, Paul EA, Cotrufo MF (2018) Incorporation of shoot versus root-derived $13 \mathrm{C}$ and $15 \mathrm{~N}$ into mineral-associated organic matter fractions: results of a soil slurry incubation with dual-labelled plant material. Biogeochemistry 137:379-393. https://doi.org/10.1007/s10533-018-0428-z

Palm CA, Giller KE, Mafongoya PL, Swift MJ (2001) Management of organic matter in the tropics:Translating theory into practice. Nutr Cycl Agroecosystems 61:63-75.https://doi.org/10.1023/A: 1013318210809
Piepho HP, Büchse A, Richter C (2004) A mixed modelling approach for randomized experiments with repeated measures. J Agron Crop Sci 190:230-247. https://doi.org/10.1111/j.1439-037X. 2004.00097.x

Puttaso A, Vityakon P, Rasche F et al (2013) Does organic residue quality influence carbon retention in a tropical sandy soil? Soil Sci Soc Am J 77:1001. https://doi.org/10.2136/sssaj2012.0209

Puttaso A, Vityakon P, Saenjan P et al (2011) Relationship between residue quality, decomposition patterns, and soil organic matter accumulation in a tropical sandy soil after 13 years. Nutr Cycl Agroecosystems 89:159-174. https://doi.org/10.1007/ s10705-010-9385-1

Samahadthai P, Vityakon P, Saenjan P (2010) Effects of different quality plant residues on soil carbon accumulation and aggregate formation in a tropical sandy soil in Northeast Thailand as revealed by a 10-year field experiment. L Degrad Dev 21:463-473. https:// doi.org/10.1002/ldr.982

Sanghaw R, Iwai CB, Choosai C, Vityakon P (2017) Initial contents of residue quality parameters predict effects of larger soil fauna on decomposition of contrasting quality residues. Agric Nat Resour 51:338-346. https://doi.org/10.1016/j.anres.2017.11.003

Segoli M, De Gryze S, Dou F et al (2013) AggModel: A soil organic matter model with measurable pools for use in incubation studies. Ecol Modell 263:1-9. https://doi.org/10.1016/j.ecolmodel.2013. 04.010

Six J, Bossuyt H, Degryze S, Denef K (2004) A history of research on the link between (micro)aggregates, soil biota, and soil organic matter dynamics. Soil Tillage Res 79:7-31. https://doi.org/10. 1016/j.still.2004.03.008

Six J, Elliott E, Paustian K (2000) Soil macroaggregate turnover and microaggregate formation: a mechanism for $\mathrm{C}$ sequestration under no-tillage agriculture. Soil Biol Biochem 32:2099-2103. https:// doi.org/10.1016/S0038-0717(00)00179-6

Tisdall JM, Oades JM (1982) Organic matter and water-stable aggregates in soils. J Soil Sci 33:141-163. https://doi.org/10.1111/j. 1365-2389.1982.tb01755.x

Totsche KU, Amelung W, Gerzabek MH et al (2017) Microaggregates in soils. J Plant Nutr Soil Sci 181:1-33. https://doi.org/10.1002/ jpln.201600451

Vance ED, Brookes PC, Jenkinson DS (1987) An extraction method for measuring soil microbial biomass C. Soil Biology \& Biochemistry 19:703-707. https://doi.org/10.1016/0038-0717(87)90052-6

Vityakon P, Meepech S, Cadisch G, Toomsan B (2000) Soil organic matter and nitrogen transformation mediated by plant residues of different qualities in sandy acid upland and paddy soils. NJAS Wageningen J Life Sci 48:75-90. https://doi.org/10.1016/S15735214(00)80006-8

Walkley A, Black IA (1934) An examination of the degtjareff method for determining soil organic matter, and a proposed modification of the chromic acid titration method. Soil Science 37:29-38. https://doi.org/10.1097/00010694-193401000-00003

Zhang X, Xin X, Yang W et al (2019) Short-term decomposition, turnover and retention of residue-derived carbon are influenced by the fertility level in a sandy loam soil. Geoderma 349:68-78. https://doi.org/10.1016/j.geoderma.2019.04.043

Publisher's Note Springer Nature remains neutral with regard to jurisdictional claims in published maps and institutional affiliations. 